\title{
A Comparative Analysis on Export Complexity and Export Technology Structure of Mechanical and Electrical Products between China, Japan and Korea
}

\author{
Guoe Xie, Shufen Zheng \\ Business School, East China University of Science and Technology, Shanghai, China \\ Email: gracexie@ecust.edu.cn
}

How to cite this paper: Xie, G.E and Zheng, S.F. (2019) A Comparative Analysis on Export Complexity and Export Technology Structure of Mechanical and Electrical Products between China, Japan and Korea. Modern Economy, 10, 2120-2133. https://doi.org/10.4236/me.2019.109133

Received: September 5, 2019

Accepted: September 21, 2019

Published: September 24, 2019

Copyright $\odot 2019$ by author(s) and Scientific Research Publishing Inc. This work is licensed under the Creative Commons Attribution International License (CC BY 4.0).

http://creativecommons.org/licenses/by/4.0/ (c) (i) Open Access

\begin{abstract}
Using the method of export complexity index, this paper calculates the export trade structure and technology content of mechanical and electrical products between China, Japan and South Korea from 2000 to 2016 based on the 6-digit code of UN COMTRADE database, and examines the differences between them in export technology complexity and export technology structure. The results show that although the export technology complexity of China's mechanical and electrical products has been improved to some extent, it is still not high. Among the mechanical and electrical products exported by China, there are more products with low complexity and medium complexity, while Japan's products with high complexity are obviously more than China's, and Korea's products with low complexity are less than China's. Based on this, this paper puts forward some suggestions on upgrading the export technology structure of China's mechanical and electrical products.
\end{abstract}

\section{Keywords}

Mechanical and Electrical Products of China, Japan and Korea, Export Technology Complexity, PRODY Index, EXPY Index

\section{Introduction}

China, Japan and South Korea are the three most powerful and active economies in East Asia, and they are also typical representatives of developing countries, developed countries and newly industrialized countries in East Asia. The trade relations between China, Japan and South Korea are inseparable and important 
trading partners. According to the statistics of Chinese Customs in 2017, China is Korea's largest trading partner and its largest export and import market, and Korea is China's third largest trading partner. According to the statistics of Japan Customs in 2017, China is Japan's second largest export trading partner and the first import trading partner. Therefore, the comparative study of economic and trade among the three countries has always been a topic of concern to scholars.

In recent years, the focus of discussion on China's export trade has gradually shifted from export scale to export structure and product quality. The index system to measure a country's trade technology structure based on degree of Sophistication has become a hot topic in the field of international trade [1] [2] [3] [4]. In China, Yao and Zhang [5], who first used this method, measured the technology content of China's export processing industry from 1997 to 2002, and finally concluded that the decline of domestic technology content of China's export products may be only a temporary phenomenon. From then on, Zhu et al. [6] analyzed the changes of the technological structure of China and India's export products, and found that both countries' export technology level and technological height have increased significantly, but overall, the improvement degree of China's export technological structure is much higher than India's. There are complementarities in the structure of export trade and the technological level of trade products between the two countries. Based on the export data of metal products from 52 economies in the world from 1993 to 2006, Huang et al. [7] calculated the export complexity and constructed a model. It is believed that the driving force of China's export complexity has changed from export-driven to economic growth-driven. Fan and Chang [8] analyzed the technical structure of import trade of China, Japan and South Korea in many aspects by using the measurement method of the technical structure of export trade. They believe that compared with the structure of Japanese and Korean import products, China's import trade shows a special structure with a large proportion of products at both ends and a small proportion of intermediate products. Guo and Yang [9] measured the export complexity of four high-tech industries: medicine, computer and office equipment, electronic and communication equipment, medical equipment and instruments. They concluded that the export complexity of high-tech manufacturing industry in China mainly comes from economic growth rather than technological innovation. Huang and Zhang [10] summarized the research progress on the definition, measurement, anomaly and internal mechanism of export complexity in foreign literature. He and Tian [11] calculated the export complexity of agricultural products of China, Japan and South Korea from 2000 to 2010, and found that Japan's technological structure is still the highest, followed by South Korea. There is still a gap between China and Japan and Korea. Tong [12] calculated the export complexity of high-tech products from China, Japan and Korea based on HS4 code, and analyzed the technical characteristics and development trend of high-tech products from China, Japan and Korea. 
Mechanical and electrical products not only account for a larger share of the total exports of China, Japan and Korea, but also account for a larger proportion of trade among the three countries. In 2017, China, Japan and Korea accounted for $58.38 \%, 64.15 \%$ and $64 \%$ of their total exports respectively. In the trade among the three countries, mechanical and electrical products account for $47.72 \%$ of Sino-Japanese trade volume and $51.73 \%$ of Sino-Korean trade volume. It can be seen that mechanical and electrical products play an important role in the study of the trade structure and evolution trend of the three countries. Many people think that China has become a big trading country in mechanical and electrical products, but is it a powerful trading country in mechanical and electrical products? Compared with Japan and Korea, how about the export technology content of China's mechanical and electrical products? What's the difference between them? There is a lack of research on these issues in the literature, a few of which are related to agricultural products and high-tech products, but they are only based on HS4-digit coding to measure the complexity of export technology, and lack of more detailed product-level analysis.

To this end, this paper will use the method of export complexity index to measure the changes of export technology content of mechanical and electrical products between China, Japan and South Korea from 2000 to 2016 based on UN COMTRADE 6-digit data, and compare the differences of export technology structure between China, Japan and South Korea. The mechanical and electrical products studied in this paper include seven categories of HS84 HS90 products [13]. There are 1046 kinds of mechanical and electrical products using HS six-digit coding. Compared with the current research on mechanical and electrical products based on HS four-digit coding, more specific product level information can be obtained.

\section{Analysis on the Development Trend of China, Japan and Korea's Export of Mechanical and Electrical Products}

\subsection{Overview of China, Japan and Korea's Respective Export Development of Mechanical and Electrical Products}

With the development of economic globalization, the trade volume of China, Japan and South Korea to the world is increasing, especially in the field of mechanical and electrical products. China has become the world's largest exporter of mechanical and electrical products. In 2016, China's export volume reached 1057.3 billion US dollars, accounting for $16.2 \%$ of the world's total exports, while Japan's export volume reached 419 billion US dollars, ranking fourth in the world, accounting for $6.4 \%$ of the world's total exports; Korea's export volume was 318.3 billion US dollars, the sixth in the world, accounting for $4.9 \%$ of the world's total exports (see Figure 1). It can be seen that China, Japan and South Korea play a decisive role in the export of mechanical and electrical products in the world.

China has the lowest starting point in the development among the three 


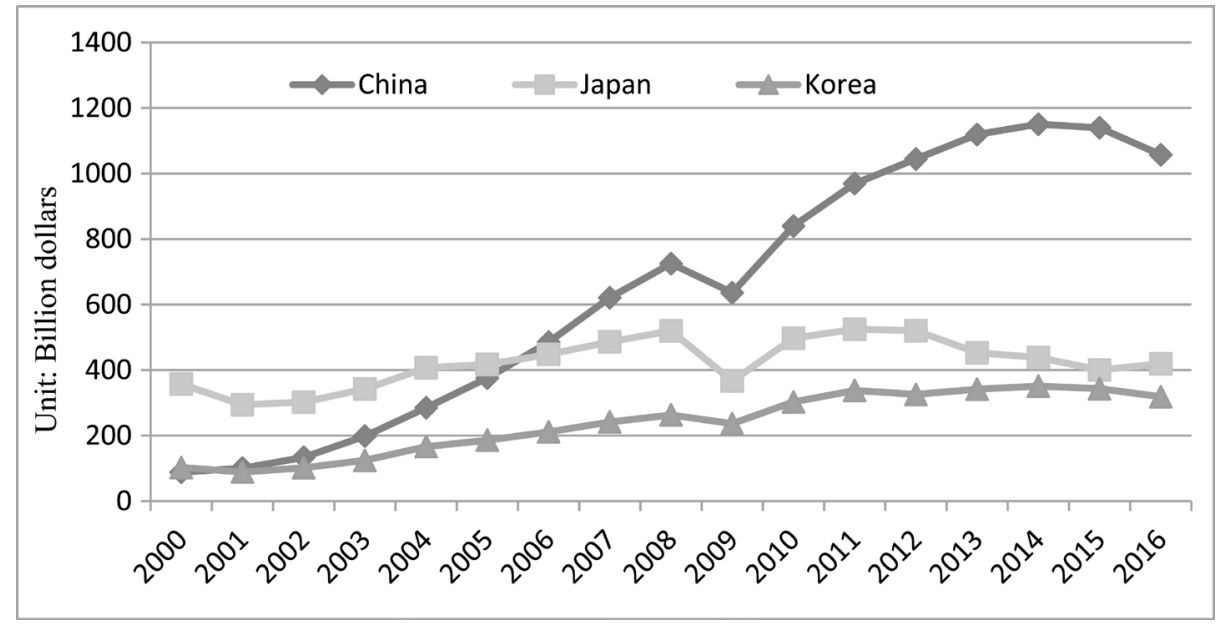

Source: Calculated by author based on UN Comtrade database (https://comtrade.un.org/data/).

Figure 1. Exports of mechanical and electrical products from China, Japan and Korea to the world.

countries, but the fastest pace of development. Before 2006, the export volume of China's mechanical and electrical products is not much different from that of Japan and Korea. After 2006, China has gradually shown its advantages, and its advantages are growing. In 2000, China's exports of mechanical and electrical products amounted to 8.84 million. Due to the impact of reform and opening-up and accession to the World Trade Organization, China's mechanical and electrical products grew fastest from 2000 to 2008. After the world economic crisis in 2009, China's exports of mechanical and electrical products continued to grow at a faster rate. Growth did not ease until 2014. In 2016, China's exports of mechanical and electrical products have increased more than ten times. South Korea has increased by 3.1 times from $\$ 102.4$ billion in 2000 to 2016 at a more balanced rate, and the gap has gradually narrowed compared with Japan's exports. Japan's growth rate is the slowest. It started at 357.4 billion US dollars in 2000. After 16 years of development, it has only increased by about 1.2 times. It has been in a stable state. This shows that Japan's electromechanical products industry started earlier and its technology has developed to a higher level. It can be seen that in 2009, due to the impact of the economic crisis, the export volume of mechanical and electrical products of the three countries has declined, of which South Korea declined the least, indicating that it was the least affected by the economic crisis.

\subsection{An Overview of the Export of Mechanical and Electrical Products between China, Japan and Korea}

The trade volume of mechanical and electrical products between China, Japan and Korea is also increasing year by year. The total trade volume of mechanical and electrical products between the three countries in 2000 was only US $\$ 63.9$ billion, while in 2016 it rose to US\$290.2 billion, an increase of 4.5 times. Figure 2 shows that in 2016, the trade volume of mechanical and electrical products between 


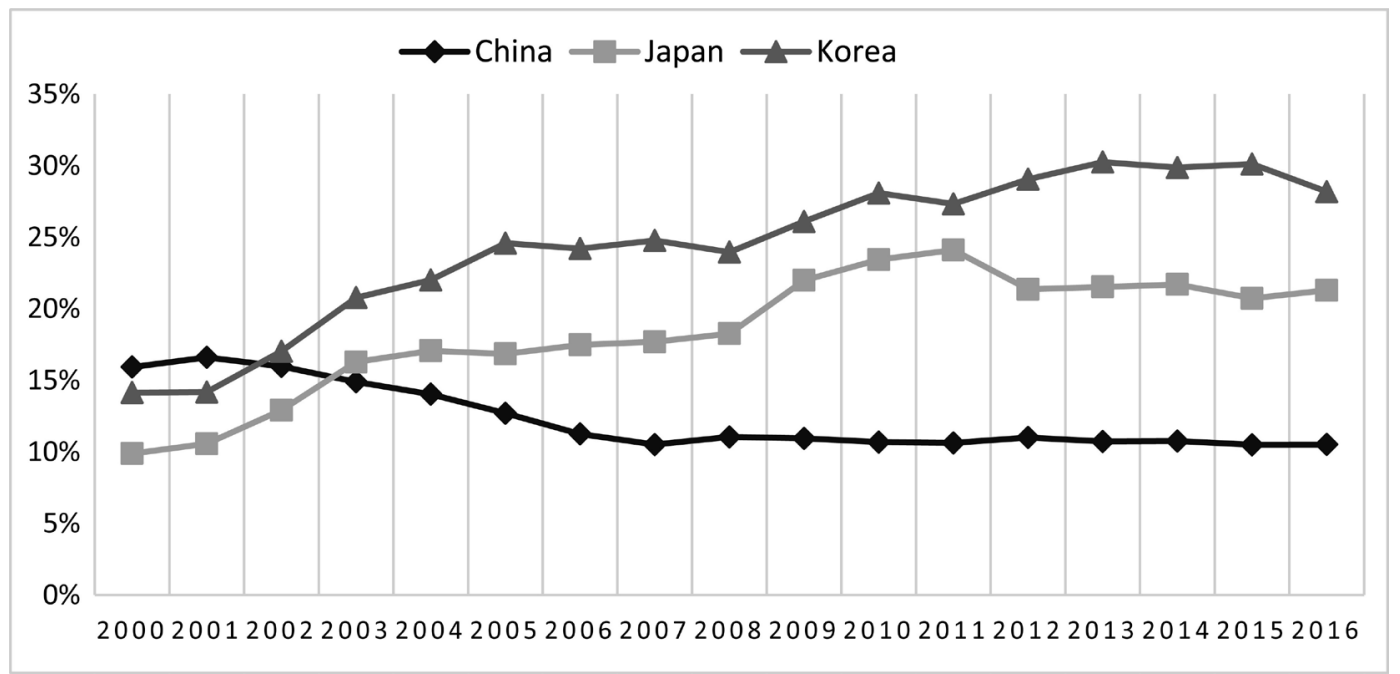

Source: Calculated by author based on UN Comtrade database.

Figure 2. The proportion of mechanical and electrical products exports between China, Japan and Korea in the total export of mechanical and electrical products of the country.

China, Japan and Korea accounted for $10.5 \%, 21.2 \%$ and $28.1 \%$ of the total trade volume of mechanical and electrical products, respectively. The trade volume of mechanical and electrical products between China, Japan and Korea accounted for a large proportion in each country. Since 2000, the percentage of Japan's trade in mechanical and electrical products between China and Korea has increased year by year, as has Korea's trade with China and Japan. Japan increased from $10 \%$ to $21 \%$ and Korea from $14 \%$ to $28 \%$, but China's trade in mechanical and electrical products with Japan and Korea decreased by $5 \%$. The main reason for this is that the three countries have different international division of labor in mechanical and electrical products. As a developed country, Japan and Korea export high-tech mechanical and electrical products. The trade mode between the three countries is usually Japan and Korea export high-tech mechanical and electrical products to China. China provides low-end mechanical and electrical parts for Japan and Korea or serves as processing origin of mechanical and electrical products for Japan and Korea, and then exports to other parts of the world.

\section{Construction of Export Complexity Index}

The technology content of products is reflected by R\&D cost, but the cost of $\mathrm{R} \& \mathrm{D}$ in industry and product level cannot be accurately calculated. Hausmann [1] proposed the concept of complexity to measure the technology content of products. Hausmann et al. [1] combined per capita income with export, constructed export complexity index-EXPY index, which was used to analyze the technology content of export products, industries or exporting countries. The calculation of the index can be carried out in two steps.

Firstly, the PRODY index is constructed. The weighted average of the per capita GDP of the exporting country is used to express the complexity or added 
value of each product. The weight is the proportion of the export proportion of a country's product to the sum of the world's exports. The formula is as follows:

$$
\operatorname{PRODY}_{j}=\sum_{c} \frac{\frac{E X_{j c}}{E X_{c}}}{\sum_{c} \frac{E X_{j c}}{E X_{c}}} Y_{c}
$$

Among them, $E X_{j c}$ denotes the export volume of $j$ products of country $c$, $E X_{c}$ denotes the total export value of country $c$. Molecule is the proportion of a country's exports of $j$ product in its total exports. The denominator is the sum of the export proportions of $j$ products from all countries. In order to improve work efficiency and achieve better results, this paper selected 25 sample countries, because their total trade in 2016 accounted for more than $90 \%$ of the world's total, which can represent the overall global trade situation. $Y_{c}$ denotes the per capita GDP of C country. The PRODY values of different products can be obtained by multiplying $Y_{c}$ with the export weights of $j$ products from different countries and adding them together. At this time, the PRODY value can be regarded as the world output level of each product after eliminating the distortion caused by the income level. This index also reflects the technical complexity of each product. According to the size of the index, high-complexity technical products, medium-complexity technical products and low-complexity technical products can be distinguished. In this paper, the PRODY values of all six-digit codes of mechanical and electrical products are calculated, which can represent the technical complexity of each kind of mechanical and electrical products.

Secondly, the EXPY index is constructed. The exporting complexity of a country or an industry (or the index of export structure's heightening) can be obtained by weighting the exporting share of the subdivided products of an industry with the PRODY value of each product. This makes it possible to use trade data instead of hard-to-calculate product-level $R \& D$ data to analyze the export technology structure of a country or region, thus reflecting the export technology content and international division of labor status of a country or region.

$$
E X P Y_{C i}=\sum_{j}\left(\frac{E X_{c i j}}{E X_{c i}}\right) P R O D Y_{j}
$$

The EXPY index is the weighted average value of PRODY of all mechanical and electrical products exported from country $\mathrm{C}$. This value reflects the complexity of export technology of a country's mechanical and electrical products industry as a whole, and reflects the technological content and competitiveness of the country's mechanical and electrical industries. This paper calculates the average EXPY values of China, Japan, Korea and 25 selected countries, representing the technical level of each country in the field of mechanical and electrical products. 


\section{Calculation Results and Analysis}

\subsection{Evolution of Export Complexity of TOP2 Mechanical and Electrical Products in China, Japan and Korea}

Table 1 shows the evolution of six kinds of mechanical and electrical products and their PRODY values with the largest export volume of China, Japan and Korea based on 2016. According to statistics, HS851712 (Radio Telephone) and HS847130 (Portable Automatic Data Processing Equipment) are the two most exported mechanical and electrical products in China in 2016, with the export volume reaching 116 billion US dollars and 79.6 billion US dollars. At the same time, China is also the world's largest exporter of these two products, accounting for $53 \%$ and $70 \%$ of the world's total exports, respectively. However, the PRODY values of these two products are relatively small, and their development is relatively slow. They belong to products with low technological complexity. This shows that China is mainly engaged in processing trade-oriented work, and the technical requirements are not high. The output of HS851712 exported by Japan is very small, only about US $\$ 0.15$ billion, which is a strong contrast with China. At the same time, it also shows that Japan's production of low-tech complex products is very small. According to this table, Japan mainly depends on the export of high-tech products to some developing countries, including China. It uses a large number of labor forces for processing and production.

HS870323 ( $1.5<$ displacement $<2$ litre ignited reciprocating piston internal combustion engine vehicle) and HS870324 $(3<$ displacement $<4$ litre ignited reciprocating piston internal combustion engine vehicle) are the two most exported electromechanical products in Japan in 2016. Both products belong to the automotive industry, and the PRODY value is very large, which also confirms Japan's leading position in this industry. Both of these products have a relatively early starting point, and the technical complexity of the starting point is high, which indicates that Japan has had a relatively excellent technical level since 2000. At the same time, the PRODY value of HS870323 has also increased greatly in recent years. It is not difficult to see that Japan has been making continuous progress in this respect.

Table 1. Evolution of PRODY value of technical structure of export trade of mechanical and electrical products between Japan and Korea.

\begin{tabular}{cccccccccc}
\hline HS Code & 2000 & 2002 & 2004 & 2006 & 2008 & 2010 & 2012 & 2014 & 2016 \\
\hline HS851712 & - & - & - & - & $20,491.32$ & $16,431.75$ & $15,134.33$ & $15,373.70$ & $18,530.56$ \\
HS847130 & $28,533.45$ & $19,525.50$ & $21,157.55$ & $17,629.57$ & $16,937.95$ & $22,456.03$ & $22,127.37$ & $21,727.43$ & $23,395.14$ \\
HS870323 & $29,375.63$ & $30,898.18$ & $37,690.41$ & $35,852.81$ & $36,875.53$ & $36,748.71$ & $38,406.70$ & $37,844.61$ & $39,059.67$ \\
HS870324 & $42,091.28$ & $42,856.52$ & $46,232.19$ & $44,916.54$ & $42,805.71$ & $44,126.60$ & $45,792.15$ & $45,926.28$ & $47,561.64$ \\
HS854232 & - & - & - & - & $28,509.74$ & $28,730.47$ & $29,166.13$ & $30,904.91$ & $31,266.27$ \\
HS854231 & - & - & - & - & $32,093.20$ & $28,622.00$ & $26,965.01$ & $28,524.56$ & $28,715.36$ \\
\hline
\end{tabular}

Source: Calculated by author based on UN Comtrade database. 
HS854232 (Integrated Circuit for Memory) and HS854231 (Integrated Circuit for Processor and Controller) are the two most exported products in South Korea in 2016. Their technical complexity is in the middle of the above two types of products, indicating that the technological level of South Korea is between China and Japan. The development of Korea and China in the three countries started relatively late, and there was no export of these two products before 2006. However, they developed rapidly and could export a large number of products with high complexity in a few years.

It is not difficult to see the role played by China, Japan and Korea in international production from the above table. Because of the relatively backward technology level, China imports a large number of high complexity mechanical and electrical products from foreign countries, while exporting low and medium technology complex mechanical and electrical products with the advantage of human cost. This kind of trade not only promotes the trade between China, Japan and South Korea, but also helps China learn advanced technology from other countries.

At the same time, we calculated the PRODY values of all 1046 products, and according to the relative value segmentation method [14], we divided the technical complexity of mechanical and electrical products into five categories: higher, high, medium, low and lower. Because the research object is too large, we cannot list them one by one, so Table 2 only lists the product codes with relatively large export volume under each category.

Table 2 shows that higher-tech complexity and lower-tech complexity products are relatively few, and the overall distribution is "small at both ends and large in the middle". Some products have high technical complexity, such as HS90 (optical, photographic, film, metrology, inspection, medical or surgical instruments and equipment, precision instruments and equipment; parts and accessories of the above items), HS8704 (with a spark-ignited piston internal combustion engine), HS8467 (parts for other portable electric tools), HS8439 (machine parts for making or finishing paper and cardboard), HS8448 (looms and auxiliary machines using other parts and accessories), HS8440 (other book binding machines), HS8411 (parts for turbojet or turboprop engines), HS8430 (non-self-propelled tamping or compacting machinery), HS8802 (aircraft and other aviation), HS8535 (circuit fuse). China should strengthen research and investment in these industries in order to obtain higher value-added returns.

\subsection{A Comparative Analysis on Export Structure of Mechanical and Electrical Products between China, Japan and Korea}

Table 3 shows the distribution of product complexity of China, Japan and South Korea in the top 100 export volumes in 2016. According to the statistical results, China's export of mechanical and electrical products is dominated by low and medium complexity products, with no high and higher complexity products, and there is a big gap with Japan and South Korea. The export of mechanical and electrical products in Korea is similar to that in Japan, but the export of 
Table 2. Technical structure distribution of mechanical and electrical products.

\begin{tabular}{|c|c|}
\hline $\begin{array}{l}\text { Classification of Product } \\
\text { Technology Complexity }\end{array}$ & HS CODE \\
\hline $\begin{array}{l}\text { Higher Complexity } \\
(\text { PRODY } \geq 57,810)\end{array}$ & $\begin{array}{l}\text { HS902110, HS902150, HS845610, HS902129, HS853530, HS844130, } \\
\text { HS846140, HS901811, HS846090, HS844010, HS901520, HS845730, } \\
\text { HS844819 (A total of } 21 \text { kinds of mechanical and electrical products) }\end{array}$ \\
\hline $\begin{array}{c}\text { High Complexity } \\
(57,810>\text { PRODY } \geq 44,924)\end{array}$ & $\begin{array}{l}\text { HS870324, HS848620, HS841199, HS870422, HS870423, HS } 840890 \text {, } \\
\text { HS902780, HS902790, HS902190, HS880230, HS902139, HS842890, } \\
\text { HS902131 (A total of } 161 \text { kinds of mechanical and electrical products) }\end{array}$ \\
\hline $\begin{array}{c}\text { Medium Complexity } \\
(44,924>\text { PRODY } \geq 32,038)\end{array}$ & $\begin{array}{l}\text { HS870323, HS854239, HS851762, HS870332, HS880240, HS870899, } \\
\text { HS880330, HS870840, HS844399, HS850440, HS848180, HS901890, } \\
\text { HS841191 (A total of } \mathbf{5 8 3} \text { kinds of mechanical and electrical products) }\end{array}$ \\
\hline $\begin{array}{c}\text { Low Complexity } \\
(32,038>\text { PRODY } \geq 19,151)\end{array}$ & $\begin{array}{l}\text { HS854231, HS851770, HS847130, HS854232, HS847330, HS847170, } \\
\text { HS870829, HS870322, HS901380, HS847150, HS854140, HS853710, } \\
\text { HS852990 (A total of } \mathbf{2 5 4} \text { kinds of mechanical and electrical products) }\end{array}$ \\
\hline $\begin{array}{l}\text { Lower Complexity } \\
(\text { PRODY < 19,151) }\end{array}$ & $\begin{array}{l}\text { HS851712, HS852872, HS854430, HS841510, HS841810, HS852721, } \\
\text { HS901390, HS851829, HS851650, HS841451, HS841821, HS900691, } \\
\text { HS845020 (A total of } 27 \text { kinds of mechanical and electrical products) }\end{array}$ \\
\hline
\end{tabular}

Source: Calculated by author based on UN Comtrade database. Note: In order to save space, we only list specific product names with higher technical complexity as follows. HS902110: Orthopedic or Fracture Appliances (excluding Artificial Joints); HS902150: Cardiac pacemaker, excluding parts and accessories; HS845610: Machine Tool for Laser or Other Light or Photon Beams Processing; HS902129: denture fixtures; HS 853530: disconnector and intermittent switch; HS844130: Machine for manufacturing boxes, boxes, tubes, barrels or similar containers, other than by moulding; HS846140: Cutting Machine, Gear Grinder or Gear Finishing Machine; HS901811: ECG recorder; HS846090: Other; HS844010: Machine; HS901520: Theodolite and Tacheometer; HS845730: Multi-station Combination Machine Tool; HS844819: Auxiliary Machines for Machines of Categories 8444 to 8447.

Table 3. Complexity distribution of TOP100 exports of mechanical and electrical products from Japan and Korea.

\begin{tabular}{cccc}
\hline Technology Complexity & Number/China & Number/Japan & Number/Korea \\
\hline Higher & 0 & 0 & 0 \\
High & 0 & 10 & 4 \\
Medium & 35 & 56 & 47 \\
Low & 56 & 34 & 42 \\
Lower & 9 & 0 & 7 \\
\hline
\end{tabular}

Source: Calculated by author based on UN Comtrade database.

products with high complexity still lags behind that in Japan, and there are a certain number of products with lower complexity.

Figure 3 shows the distribution of export technology structure of all mechanical and electrical products in China, Japan and Korea based on PRODY values. The figure shows that the proportion of low-complexity mechanical and electrical products exported by China is decreasing from 2000 to 2016, and the proportion of low-complexity, medium-complexity and high-complexity products is increasing year by year. The proportion of lower-complexity mechanical and electrical products in Korea is decreasing faster than that in China, and the proportion is lower than that in China after 2000, and has been stable since then. 


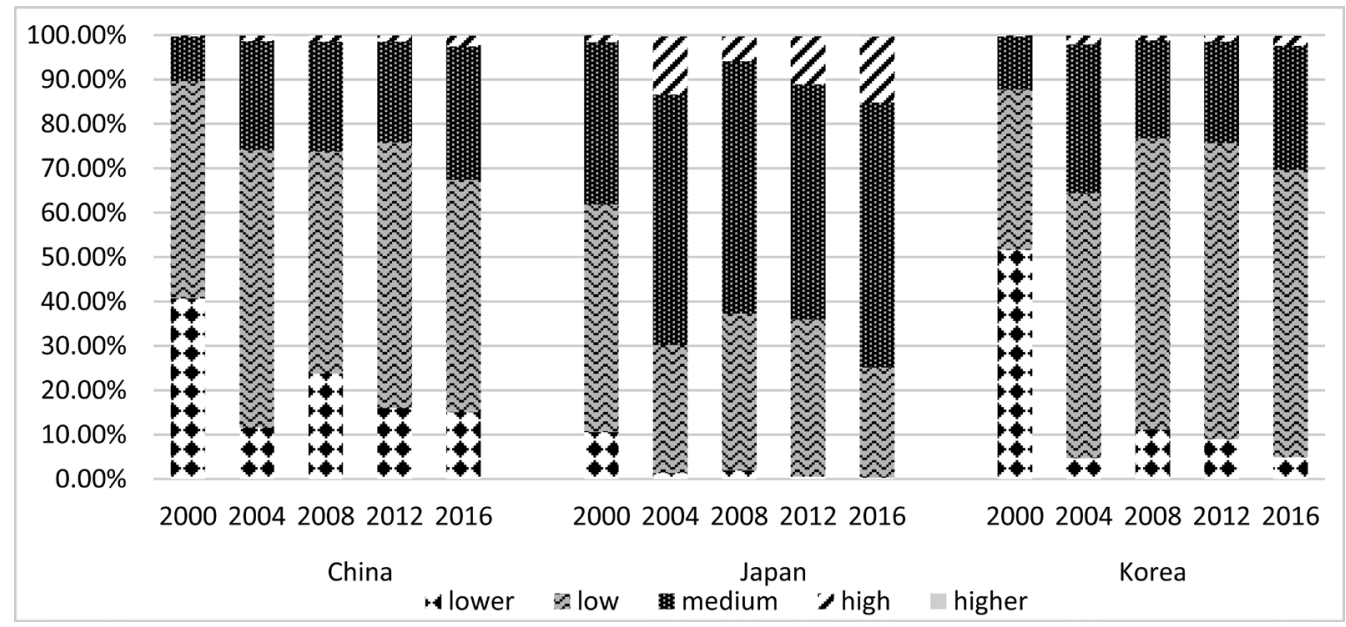

Source: Calculated by author based on UN Comtrade database.

Figure 3. The proportion of Chinese, Japanese and Korean products with different export complexity.

The proportion of low complexity products in Korea is larger and rising year by year. The proportion of medium and high complexity products is equal to that in China. The proportion of lower complexity products in Japan is very small, while the proportion of medium complexity products is steadily increasing year by year. The proportion and growth trend of high complexity products are significantly higher than those of China and Korea. The proportion of products with higher complexity in the three countries is relatively small, but the proportion of Japan is higher than that of China and Korea. Korea accounts for a larger proportion of products with higher complexity than China.

It can be concluded that Japan still shows obvious advantages in the overall technical content of mechanical and electrical products, which is superior to China and Korea. The overall technical content of China and Korea is basically the same, but the overall technical level of Korea is still higher than that of China. Since China's entry into WTO, a considerable part of the export of mechanical and electrical products belongs to processing trade. Most of Chinese enterprises are engaged in the middle and low-end processing of mechanical and electrical products, with low added value.

In terms of technology structure, the optimization degree of technology structure of mechanical and electrical products in China and Korea is obviously weaker than that in Japan, and that of Korean mechanical and electrical products is better than that of China. China's poor export technology structure is attributed to the large export volume of products with low technology and medium and low technology content. Japan has shown obvious advantages in the export of high-tech products. In the bilateral trade of mechanical and electrical products, China and Korea have a lot of low-complexity mechanical and electrical products export, so there is a certain degree of competition in low-tech products. However, the two sides have shown complementarity in the export of high-tech mechanical and electrical products. This shows that, compared with Japan and Korea, although China occupies a dominant position in low-tech products, it is 
obviously weak in medium-high and high-tech products. If the technology level of a country is judged largely by the quantity of high-tech products it produces or exports, then the overall technology level of Chinese manufacturing is lower than that of Japan and Korea. In addition, although South Korea is still weaker than Japan in general, it has a competitive relationship with Japan in low and medium technology content products.

\subsection{The Evolution of the Technical Complexity of the Overall Export of Mechanical and Electrical Products of China, Japan and Korea}

This paper chooses the EXPY value of the top 25 countries in the world (which account for $90 \%$ of the world's total exports) as the world average, and uses it as a reference frame to study the evolution of the overall export technology complexity of mechanical and electrical products in China, Japan and Korea. Figure 4 shows that the EXPY index of mechanical and electrical products in China, Japan and Korea is on the rise in general from 2000 to 2016. In stages, the EXPY index grew slowly from 2001 to 2003. In 2004, the EXPY index had a great momentum because of the sharp rise in international oil prices and the continued depreciation of the US dollar exchange rate. The decline continued in 2005. In 2008, the EXPY index of mechanical and electrical products in the three countries declined due to the impact of the global financial crisis. Japan's EXPY index has been significantly higher than China and Korea, and higher than the average of TOP25 countries. The EXPY index of China and Korea in 2000 is similar. With the development of Korea's mechanical and electrical industry, the EXPY index of its mechanical and electrical products exports is gradually higher than that of China and has maintained its advantages. The EXPY index of China and Korea is lower than the average of TOP 25 countries in the world. There is a big gap between China and Japan.

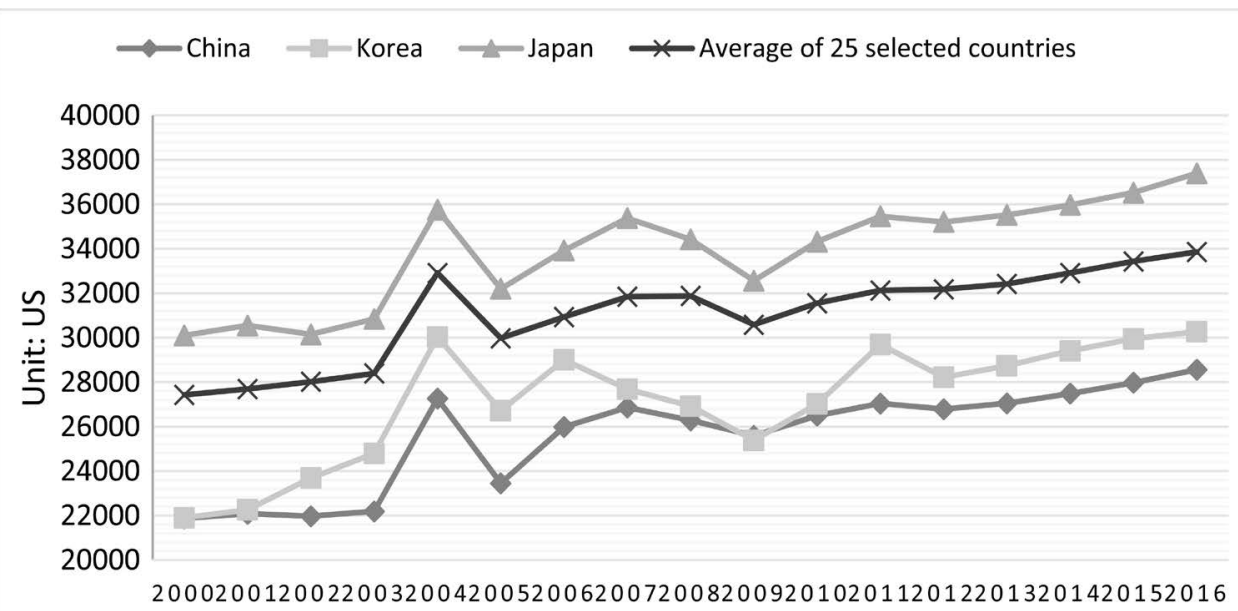

Source: Calculated by author based on UN Comtrade database.

Figure 4. EXPY value of mechanical and electrical products export from China, Japan and Korea. 


\section{Conclusions and Suggestions}

This paper finds that although the export technology complexity of China's mechanical and electrical products has been improved to some extent, it is still not high enough. Among the mechanical and electrical products exported by China, there are more products with low complexity and medium complexity, while Japan's products with high complexity are obviously more than China's, and Korea's products with low complexity are less than China's. From the perspective of technology content, the gradient level between China and Korea is relatively small, and the gap between China and Japan is large. Based on the above analysis, this paper puts forward the following suggestions to promote the upgrading of export technology content of mechanical and electrical products in China.

Actively promote and invest in the development of science and technology and education. The electromechanical industry is capital-intensive, knowledge-intensive and technology-intensive, which needs sufficient R\&D investment and human capital accumulation. The government and the electromechanical enterprises must have sufficient budget for scientific and technological innovation every year. Educational development is an important means of accumulating human capital. The government should further increase investment in education, encourage schools to reform teaching assessment methods, improve the innovative thinking ability of the younger generation, and establish a sound vocational education system. Vocational schools should strengthen cooperation with enterprises, enable students to receive excellent vocational and technical training, and reserve a large number of engineering and technical personnel for the country. In this way, we can lay a technological, financial and human foundation for improving the technological complexity of mechanical and electrical products export.

Continue to promote economic development and maintain stable economic growth. Per capita GDP plays a more direct role in promoting the export technology complexity of mechanical and electrical products, which has been shown in the calculation formula of export technology complexity. Per capita GDP is the embodiment of a country's comprehensive strength. The increase of per capita GDP means that the economy is in the growth stage. Enterprises are optimistic about the future and are willing to invest more resources to produce high-tech products. On the other hand, with the increase of per capita GDP, consumers' demand for high-tech electromechanical products increases. This can promote enterprises to produce mechanical and electrical products with higher technology content from the demand side to meet market needs. Therefore, we must continue to promote economic development and maintain stable economic growth.

Encouraging the introduction of more foreign-invested enterprises in high-tech mechanical and electrical industries. Many studies have confirmed the technology spillover effect of FDI. Local enterprises can learn and absorb the advanced technology and design capabilities of transnational investment me- 
chanical and electrical enterprises, learn from their management experience, improve their technical level and product quality, thus narrowing the technological gap with developed countries. Therefore, the government can encourage more foreign-invested enterprises in high-tech electromechanical industry by adjusting the policy of attracting investment. At the same time, the government should improve the intellectual property protection system, enhance the intensity of intellectual property protection, provide a good business environment for foreign investment, and attract more foreign investment enterprises with high quality and high technology. In this way, it is conducive to improving the technological complexity of China's export.

Strengthen trade cooperation with Japan, Korea and other developed countries in mechanical and electrical products. The export technology complexity of Japanese and Korean mechanical and electrical products is higher than that of China. China should strengthen trade cooperation with Japan and South Korea so as to increase the degree of technological openness among the three countries, thus providing opportunities for enterprises to learn the key points of advanced technology and enhance the technological content of products. In addition, we should fully allocate resources in the intra-industry trade of mechanical and electrical products with developed countries, continue to give full play to existing advantages, absorb advanced experience of the development of mechanical and electrical products industry in developed countries, pay more attention to product quality and improve the technical content of mechanical and electrical products in China.

\section{Acknowledgements}

This study is supported by the National Social Science Foundation General Program (12BJY009), the National Natural Science Foundation (71673087), and Shanghai Municipal Philosophy and Social Sciences Planning General Program (2018BJB025).

\section{Conflicts of Interest}

The authors declare no conflicts of interest regarding the publication of this paper.

\section{References}

[1] Ricardo, H., Hwang, J., and Rodrik, D. (2005) What You Export Matters. Journal of Economic Growth, 12, 1-25. https://doi.org/10.1007/s10887-006-9009-4

[2] Sanjaya, L., Weiss, J. and Zhang, J. (2006) The 'Sophistication' of Exports: A New Trade Measure. World Development, 34, 222-237. https://doi.org/10.1016/j.worlddev.2005.09.002

[3] Schott, P. (2008) The Relative Sophistication of Chinese Exports. Economic Policy, 23, 6-49. https://doi.org/10.1111/j.1468-0327.2007.00195.x

[4] Van Assche, A. and Gangnes, B. (2010) Electronics Production Upgrading: Is China Exceptional? Applied Economics Letters, 5, 477-482. 
https://doi.org/10.1080/13504850701765101

[5] Yao, Y. and Zhang, Y. (2008) Dynamic Study on the Upgrading of Domestic Technological Content of China's Exports: Evidence from China, Jiangsu Province and Guangdong Province. Chinese Social Sciences, No. 2, 67-82+205-206.

[6] Zhu, S., Chen, Y. and Xie, R. (2009) "Dragon-Elephant Debate" and "Dragon-Elephant Dance": An Analysis of Sino-Indian Trade Relations Based on Export Technology Structure. Statistical Research, 26, 25-32.

[7] Huang, X., Chen, X. and Liu, H. (2010) Measurement of Industrial Export Complexity and Analysis of Its Dynamic Evolution Mechanism: An Empirical Study on Metal Products Exports of 52 Economies from 1993 to 2006. Management World, No. 3, 44-55.

[8] Fan, A. and Chang, L. (2010) Measurement and Comparison of Technology Structure of Import Trade between China, Japan and Korea. Economist, No. 8, 47-53.

[9] Guo, J. and Yang, Y. (2010) Study on Economic Growth, Technological Innovation and Export Complexity of China's High-Tech Manufacturing Industry. Journal of International Trade, No. 12, 91-96.

[10] Huang, Y.M. and Zhang, W. (2012) Overseas Research Progress on Export Complexity. Journal of International Trade, No. 3, 167-176.

[11] He, M., Tian, W. and Cassey, A. (2012) Technical Structure and Evolution of Agricultural Products Export Trade between China, Japan and Korea: An Empirical Study Based on Export Complexity. Journal of Agrotechnical Economics, No. 5, 104-113.

[12] Tong, B. (2012) Study on the Technical Characteristics and Evolution Trend of High-Tech Products Export Trade between China, Japan and South Korea: An Empirical Study Based on Export Complexity. Finance \& Trade Economics, No. 10, 93-101.

[13] Pei, H., Wang, Y. and Kou, Y. (2017) Empirical Study on Intra-Industry Trade of Mechanical and Electrical Products between China and Korea Based on the Perspective of Development Level and Influencing Factors. Journal of Xí an University of Finance and Economics, 30, 109-117.

[14] Deng, L. and Hou, M. (2017) Estimation of Technological Structure Change of China's Industrial Manufactured Products Export Based on Relative Value Segmentation Method. Journal of International Trade, No. 10, 49-60. 